\title{
Composition Of Aerosols From The Shelter Of The Chernobyl Power Plant
}

\author{
L. Darchuk ${ }^{\mathrm{a}}$, A. Worobiec ${ }^{\mathrm{a}}$, V. Khan ${ }^{\mathrm{b}}$, V. Krasnov ${ }^{\mathrm{b}}$ and R. Van Grieken ${ }^{\mathrm{a}}$ \\ ${ }^{a}$ University of Antwerp, Universiteitsplein 1, Antwerp, Belgium, 2610 \\ ${ }^{b}$ Institute for Problems of Safety of Nuclear Power Plants of National Academy of Sciences of Ukraine, \\ Kirova street 36a, Chornobyl, Kyiv region, Ukraine, 07270
}

\section{INTRODUCTION}

At present, the direct radiation exposure to the environment from the $4^{\text {th }}$ block of the Chernobyl plant has been reduced significantly due to radioactive decay. However, the molten fuel material within the concrete shelter, the so-called "Sarcophagus", is continuously releasing atmospheric aerosols, mostly due to the crystallization of the amorphous lava-like materials, fastened by its radioactivity and the repelling of these micro-crystals due to electric charging of the surface layer of the lava because of the alpha-radioactivity. These aerosols might at present constitute the major hazard from Chernobyl, not only locally but also over distances of many hundreds of km. Analysis of the aerosols can give important information to research and forecast of substance properties and state of materials containing the nuclear fuel.

\section{EXPERIMENTS AND RESULTS}

The main goal of the investigation was to study the indoor aerosol composition from a place located close to the nuclear reactor of the $4^{\text {th }}$ block of the Chernobyl power station. Aerosols were collected from a room with nuclear fuel lava. Aerosol for subsequent single particle analysis were collected by Berner cascade impactor, which enables the sampling of size-segregated particles, depending on their aerodynamic diameter. The cut-off diameters of the used impaction stages with numbers $3,4,5,6,7$ were $0.25,0.5,1.0,2.0,4.0 \mu \mathrm{m}$, respectively.

Molecular analysis of the samples was provided by a micro-Raman spectrometer (Renishaw in via, GB) with laser excitation at $785 \mathrm{~nm}$. Samples were scanned using the Synchroscan mode from 100 to $3600 \mathrm{~cm}^{-1}$, at a spectral resolution of $2 \mathrm{~cm}^{-1}$.

As an example, Fig. 1 represents a white light image of different single particle types deposited on the silver substrate of stage 4 of the Berner impactor. Moreover typical Raman spectra for rod-like single objects and agglomerates of round particles are presented. 


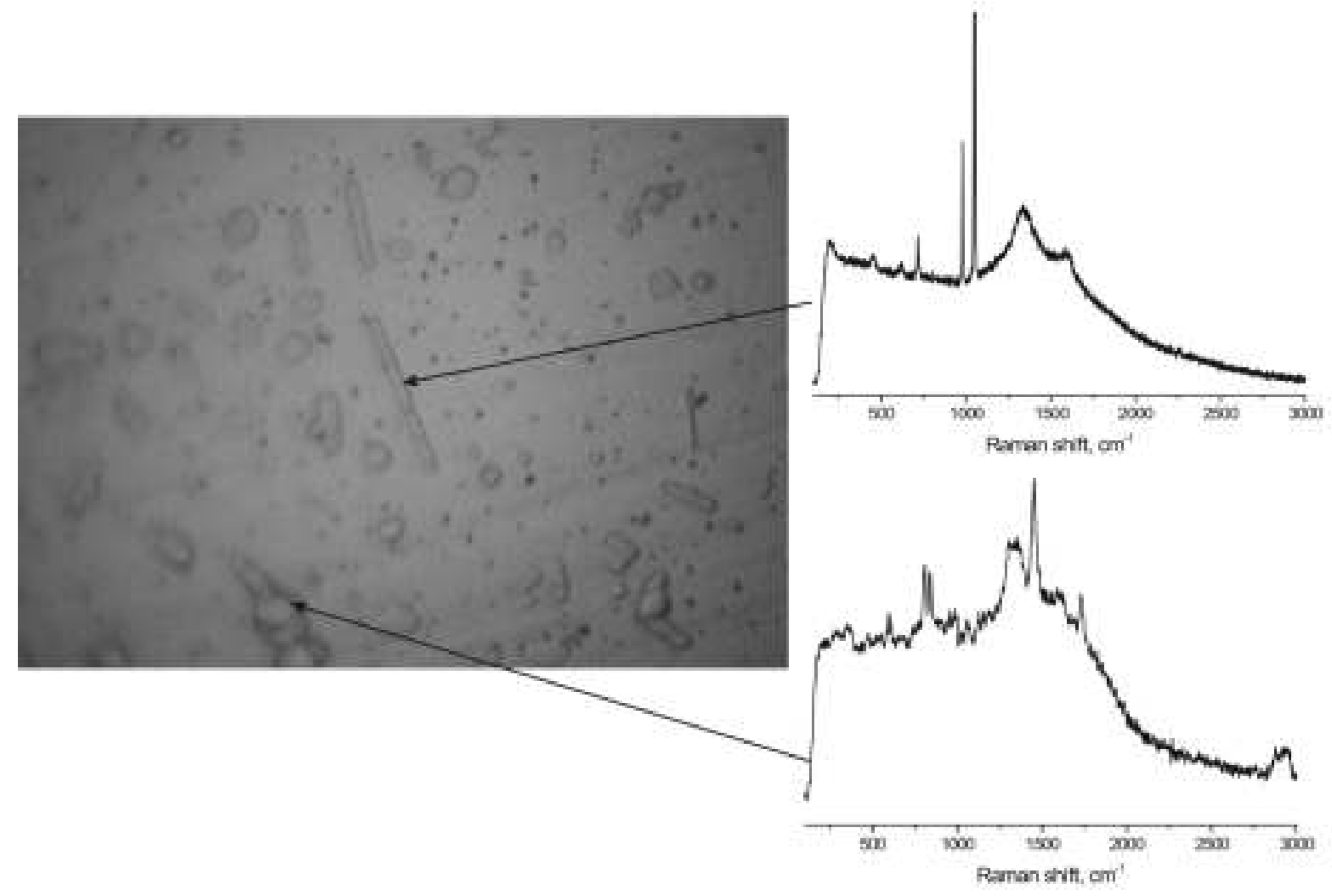

FIGURE 1. White light image of the single particles (with magnification of 1000) on a silver substrate and their Raman spectra.

Rod-like objects were detected on all stages, they had a thickness of $1 \mu \mathrm{m}$ and a length of $5 \div 50 \mu \mathrm{m}$. Raman spectra of these single objects show bands typical for ferro-axinite (at 716, 981 and $430 \mathrm{~cm}^{-1}$ ), cerussite (at 1056 and $1380 \mathrm{~cm}^{-1}$ ) and baryte (at 987 and $455 \mathrm{~cm}^{-1}$ ).

In general, for part of the particles with a diameter of $3 \div 5 \mu \mathrm{m}$, the Raman spectra consist of two strong bands, which are assigned to uranium rich particles at $811 \mathrm{~cm}^{-1}$ (vibrations of $\mathrm{U}_{3} \mathrm{O}_{8}$ ) and $833 \mathrm{~cm}^{-1}$ (vibrations of $\mathrm{UO}_{3}$ ). Weak bands at $2880 \mathrm{~cm}^{-1}$ (symmetric vibrations of $\mathrm{CH}_{2}$ ) and $2940 \mathrm{~cm}^{-1}$ (asymmetric vibrations of $\mathrm{CH}_{2}$ ) are typical for organic components. Raman spectra of more than half of the analyzed particles consist of bands assigned to organic substances with strong bands typical for haematite (at 411 and $\left.1321 \mathrm{~cm}^{-1}\right)$ and chalcocite $\left(1588 \mathrm{~cm}^{-1}\right)$.

\section{ACKNOWLEDGMENTS}

The present work was realized in the frame of the international scientific cooperation Project UA - BOF 2007 No 2837, funded by the University of Antwerp (UA) in the frame of the Special Research Fund (BOF UA). 
Copyright of AIP Conference Proceedings is the property of American Institute of Physics and its content may not be copied or emailed to multiple sites or posted to a listserv without the copyright holder's express written permission. However, users may print, download, or email articles for individual use. 